\title{
Improving the sustainability of residue management practices
}

\author{
D Cooling Alcoa Corporation, Australia
}

\begin{abstract}
Alcoa Corporation (Alcoa) has three refineries in Western Australia, at Kwinana, Pinjarra and Wagerup, with a combined capacity of around 9.4 $\mathrm{M}$ t of alumina per annum. As early as the mid-1970s, Alcoa recognised the need to investigate alternative residue management strategies. The company made a significant commitment to continuous improvement in residue management with the formation of a research and development group charged with investigating alternate storage practices. This led to a range of significant improvements to residue storage methods which have been developed and implemented over the past two decades. However, through recent long-term planning for residue storage, it has become increasingly apparent that community and government expectations are changing, and that further improvements to the way residue is managed into the future will need to be made.
\end{abstract}

Alcoa's vision for residue management is an overall transition to a more sustainable method of residue storage, where the impact on the environment and the surrounding community is being progressively reduced. The move to dry stacking was a significant step towards a more sustainable method of storage, allowing a greater volume of residue to be stored within a given footprint, and providing a stable storage area which could be used for a range of land uses once closed. Residue filtration, a process where the slurry is filtered to produce a filter cake that can be mechanically stacked, is potentially a further step in this direction.

Neutralisation of the residue was also investigated as a potential step along this pathway, as the more significant hazard associated with the residue (its high $\mathrm{pH}$ ) can be removed. Work on residue carbonation commenced in the early 1990s with preliminary laboratory testing. This work demonstrated the viability of carbonation and was followed in the mid to late 1990s with small-scale pilot testing. Encouraged by the success of these trials, a full-scale prototype of residue carbonation was installed and commissioned in mid-2000 at the Kwinana refinery. This prototype allowed detailed evaluation of both the initial treatment of a thickened residue slurry with a high-concentration $\mathrm{CO}_{2}$ gas, and the performance of this thickened slurry in a full-scale drying bed.

However, the ultimate aim in terms of sustainability of residue management is to progressively reduce the volume of residue to be stored. Dry stacking and, more recently residue filtration, have been important steps towards re-use of the residue, as it has made access and reclamation of the residue more cost-effective. Residue neutralisation may also be a key step towards re-use of the residue, as it will remove the hazardous nature of the residue, removing constraints on its handling and use. With an increased focus on re-use over recent years, a number of re-use opportunities have been developed and are progressing towards possible commercialisation.

This keynote address provides an outline of the continuous improvement journey that Alcoa has been on, providing detail of the various developments that have been adopted over the years, along with a discussion of the main drivers and benefits that supported their implementation.

Keywords: bauxite residue, dry stacking, filtration, re-use, sustainability 
